\title{
Studies on Interaction of Buffalo Brain Cystatin with Donepezil: An Alzheimer's Drug
}

\author{
Fakhra Amin and Bilqees Bano \\ Department of Biochemistry, Faculty of Life Sciences, Aligarh Muslim University, Aligarh 202002, Utar Pradesh, India \\ Correspondence should be addressed to Fakhra Amin; nabeyusuf@gmail.com
}

Received 18 April 2013; Revised 9 June 2013; Accepted 10 June 2013

Academic Editor: Francesco Panza

Copyright ( 2013 F. Amin and B. Bano. This is an open access article distributed under the Creative Commons Attribution License, which permits unrestricted use, distribution, and reproduction in any medium, provided the original work is properly cited.

\begin{abstract}
When drugs bind to a protein, the intramolecular structures can be altered, resulting in conformational change of the protein. Donepezil, an Acetyl Cholinesterase inhibitor (AChE), is commonly prescribed to patients with Alzheimer's disease (AD) to enhance cholinergic neurotransmission. It is the "first-line" agents in the treatment of Alzheimer's disease used to improve cognitive function in the disease. In the present study, a cysteine protease inhibitor (cystatin) has been isolated from buffalo brain using alkaline treatment, 40 to $60 \%$ ammonium sulphate fractionation and gel filtration chromatography on Sephadex G-75 with \% yield of 64.13 and fold purification of 384.7. The purified inhibitor (Buffalo Brain Cystatin, (BBC)) was eluted as a single papain inhibitory peak which migrated as single band on native PAGE; however, on SDS-PAGE with and without beta mercaptoethanol $(\beta \mathrm{ME}) \mathrm{BBC}$ gave two bands of M W 31.6 and $12.4 \mathrm{KDa}$, respectively. The molecular weight determined by gel filtration came out to be $43.6 \mathrm{KDa}$. The UV spectra of cystatin on interaction with donepezil suggested a conformational change in the protein. The fluorescence spectra of BC-donepezil composite show structural changes indicating $40 \mathrm{~nm}$ red shift with significant increase in fluorescence intensity of cystatin in the presence of donepezil representing an unfolding of cystatin on interaction, which is an indication of side effect of donepezil during the use of this drug.
\end{abstract}

\section{Introduction}

Brain is exposed to a variety of neuromodulating agents given as therapy. The effect of these agents apart from generation of desired activity must be assessed to understand the mechanism of action and side effects of the drug if any.

Alzheimer is the most common cause of dementia; it is a primary degenerative disease of the brain. Onset is usually late in life with increasing impairment of memory, cognition, linguistic ability, and judgment. It is a progressive brain disorder that gradually destroys a person's ability to learn, reason, and carry out daily activities $[1,2]$.

Acetylcholine is an important neurotransmitter associated with normal functioning of the brain. The greatly reduced concentration of acetylcholine in the cerebral cortex is a significant factor in $\mathrm{AD}[3,4]$. People with Alzheimer disease $(\mathrm{AD})$ have lower level of acetylcholine with the development of abnormalities in cholinergic neurons. One approach to lessening the impact of these abnormalities is to inhibit the breakdown of acetylcholine (Ach) by blocking the relevant enzyme AchE (acetyl choline esterase) [2] (Figure 1).

ChE inhibitors prevent the hydrolysis of ACh to choline and acetate in the synaptic clefts and result in activating cholinergic transmission [3].

Donepezil is a piperidine-class AChE inhibitor, rationally designed especially for $\mathrm{AD}[5,6]$. Donepezil was proven to improve cognitive function of mild to severe moderate $\mathrm{AD}$ patients and showed excellent tolerability without hepatotoxicity [7-9].

Donepezil is the first agent to be successfully developed specifically for the treatment of cognitive decline associated with Alzheimer's disease; it is marketed under the trade name of Aricept and works as an acetyl cholinesterase inhibitor [10]. It has an oral bioavailability of $100 \%$ and easily crosses the blood-brain barrier. It has a half-life of about 70 hours. It is believed that donepezil works by reducing the breakdown of acetylcholine thus increasing the concentration 


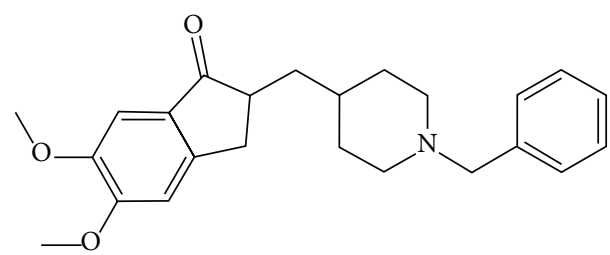

Figure 1: Structure of donepezil [17].

of acetylcholine in the brain reverting it back to its normal function [11].

Recent researches have shown that cathepsins are involved the processing of certain neuropeptides in the central nervous system (CNS) [12] where cystatin C is also present in high concentration and their concentration is suggested to play an important role in brain diseases. An imbalance between the activity of cathepsins and cystatins may lead to accumulation of potentially amyloidogenic fragments which aggregates and forms amyloid fibrils in nerve cells of $\mathrm{AD}$ brain in which cystatin concentration decreases. Potentially amyloidogenic fragments generated by imbalance of cathepsins and cystatin are released into the extracellular space. In normal persons, cysteine proteinases help in $\beta$-peptides clearing [12].

Cystatins constitute a powerful regulatory system for endogenous cysteine proteinases (cathepsins) which are often secreted or leaking from the lysosomes of dying or diseased cells [13]. They are the natural inhibitors of cysteine proteases which belongs to a super family of proteins with wide occurrence in tissues and cells [14]. On the basis of homology, inhibition of target enzymes, and presence or absence of disulphide bonds, cystatin super family has been divided into three families.

Family 1: also called as stefins include members of low molecular weight proteins $(11 \mathrm{kDa})$ which lack disulphide bonds and carbohydrate contents. This family includes cystatin A, B, stefins C, and stefins D.

Family 2: known as cystatin family represented by the inhibitors of a bit larger molecular weight proteins $(13 \mathrm{kDa})$ as compared to stefins and possesses disulphide bond towards the carboxyl terminal with no carbohydrates. They are found both in the cells and body fluids. Common example is cystatin C.

Kininogens or family 3 cystatins are large precursor molecules of the vasoactive kinins. They are single chain glycoproteins, which serve a variety of biological functions such as kinin delivery, induction of endogenous blood coagulation cascade, and mediation of the acute phase response. They are found only in blood plasma [15].

Cystatins tightly bind and inhibit the activity of cathepsins, if the activity of cathepsins is not regulated it will lead to chronic diseases [13]. It has been probed that proteinases and their endogenous inhibitors cystatins are closely associated with senile plaque, cerebrovascular amyloid deposits, and neurofibrillary tangles in Alzheimer disease [1].

In normal person, cystatins bind to cathepsins and prevent amyloid formation; however in $\mathrm{AD}$, the level of cystatin goes down and the level of cathepsins and AChE enzyme increase which leads to decreases in acetylcholine and leads to formation $\mathrm{A} \beta$ peptides, donepezil when supplemented it binds to AChE and prevents acetylcholine breakdown thus increases the level of Acetyl choline which is required for normal functioning of the brain [16]. An earlier report showed that donepezil binds with HSA and changes its free concentration in plasma showing the possibility of conformational change in protein (Figure 2) [17].

The aim was to find out if supplementation of donepezil has any effect on the activity of cystatin (major regulator of thiol proteases cathepsins $\mathrm{B}, \mathrm{H}$, and $\mathrm{L}$, etc.) in the mammalian system. If the activity of these proteases is not regulated, it will lead to protease and antiprotease imbalance, a cause of several diseases [18].

So we have investigated whether cystatin binding with donepezil has any role in the proper action of drug or leads to what kind of side effects as well as to gain knowledge about any conformational change in cystatin effecting its activity.

Our study shows that donepezil unfolds cystatin which may not be able to bind to cathepsins; therefore an imbalance of protease - antiprotease occurs in the presence of donepezil leading to considerable side effect of the drug as cystatins play significant role in several diseases like arthritis cancer and cardiovascular diseases [19]. Therefore the usage of donepezil in such patients requires further attention.

\section{Material and Methods}

\subsection{Experimental Procedures}

2.1.1. Materials. Papain (99\% purity) was obtained from Sigma Chemical Company (St. Louis, USA). Donepezil (an Alzheimer drug) was purchased from Ranbaxy (India). The solutions were prepared in $50 \mathrm{mM}$ phosphate buffer of $\mathrm{pH}$ 7.4. Salts were purchased from Merck (India). The protein concentration was determined spectrophotometrically. All other reagents were of analytical grade, and double distilled water was used throughout.

\subsubsection{Methods}

Purification of Brain Cystatins. Buffalo brain whole mass $(150 \mathrm{~g})$ was brought fresh from slaughter house in an ice bucket. It was thoroughly washed with water, thin membrane and nerves were removed by forcep, and the whole brain tissue was homogenized in $50 \mathrm{mM}$ sodium phosphate buffer $(300 \mathrm{~mL})$ of $\mathrm{pH} 7.5$ containing $0.15 \mathrm{M} \mathrm{NaCl}, 3 \mathrm{mM}$ EDTA, and 2\% n-butanol. After centrifugation at $11000 \mathrm{rpm}$ for 15 minutes at $40^{\circ} \mathrm{C}$, residue was discarded and the supernatant was further processed. The procedure involved a combination of alkaline treatment ( $\mathrm{pH} 11.0)$, ammonium sulphate fractionation, and gel filtration chromatography. Buffalo brain was homogenized and fractionated with ammonium sulfate between 40 and 60\%; it was then dialyzed against $50 \mathrm{mM}$ sodium phosphate buffer $\mathrm{pH} 7.4$ containing $0.1 \mathrm{M} \mathrm{NaCl}$. Elution profile showed two protein peaks one major and one minor called as peak-I and peak-II. Peak-I corresponding to high molecular weight Buffalo Brain Cystatin had significant 


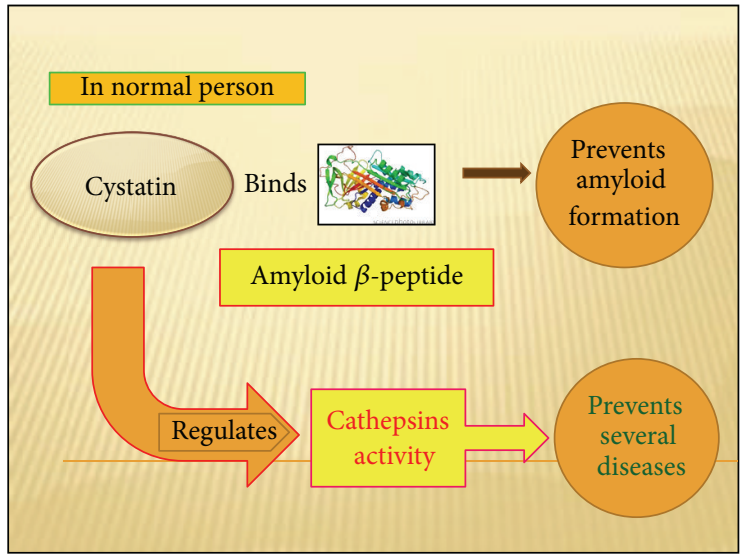

(a)

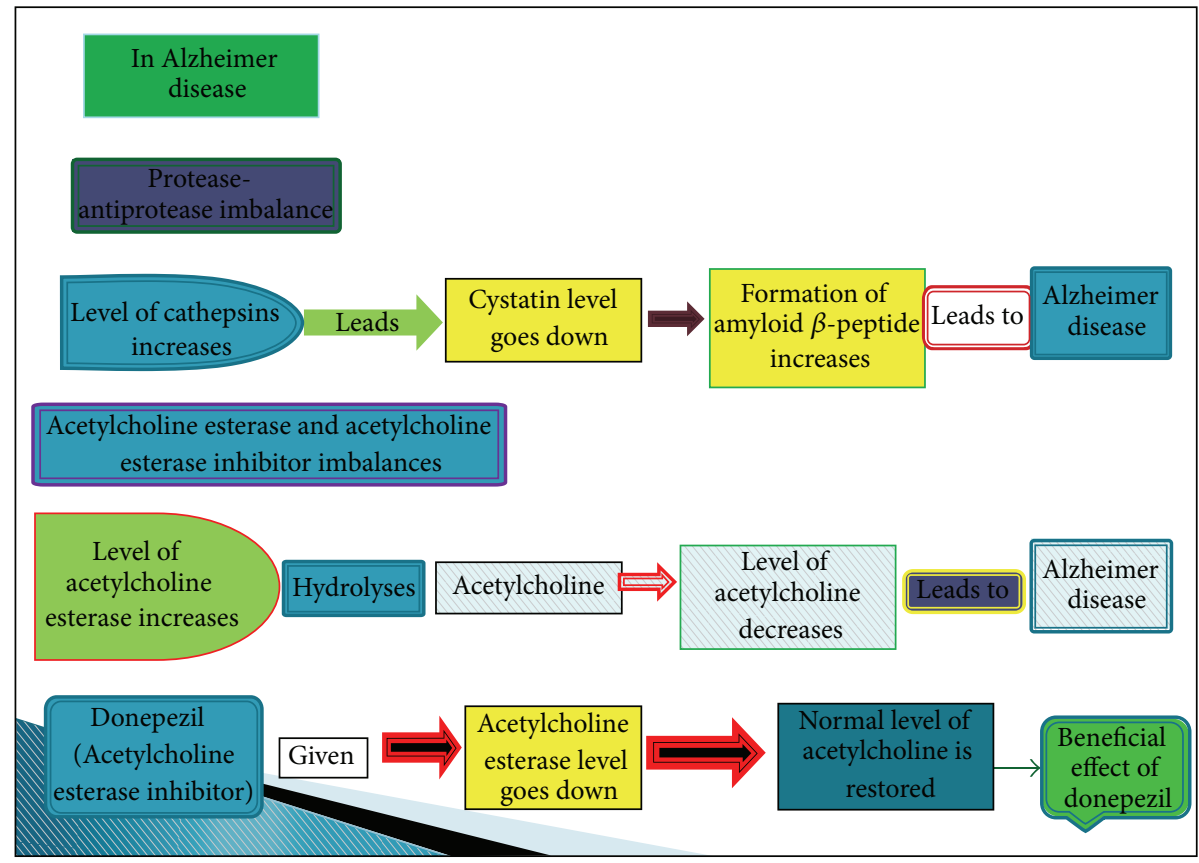

(b)

Figure 2: Proposed work.

inhibitory activity and protein content; however, peak-II with insignificant proteins concentration and low inhibitory activity was not taken into consideration for further studies. Peak-I named as BC was purified with fold purification of 384.72 and yield of $64.13 \%$. Papain inhibitory fractions of peak-I were pooled, concentrated, and checked for purity. Five milliliter fractions were collected and assayed for protein and cystatin activity. Homogeneity of the preparation was investigated by $7.5 \%$ PAGE [20].

\subsection{Interaction of Donepezil with the Cystatin}

\subsubsection{Spectroscopic Studies}

Fluorescence Spectra of Brain Cystatin with Drug. Brain cystatin $(\mathrm{BC})(1 \mu \mathrm{M})$ was incubated for $30 \mathrm{~min}$ with increasing concentrations of donepezil in $0.05 \mathrm{M}$ sodium phosphate buffer $\mathrm{pH} 7.5$ in a final reaction volume of $1 \mathrm{~mL}$ at room temperature. Drug solutions were prepared in the same buffer. Fluorescence measurements were carried out on a Shimadzu Spectrofluorometer model RF-5301PC (Shimadzu, Japan) equipped with a $150 \mathrm{~W}$ Xenon lamp and a slit width of $10 \mathrm{~nm}$ at $298 \mathrm{~K}$. The fluorescence was recorded in wavelength region $300-400 \mathrm{~nm}$ after exciting the protein at $280 \mathrm{~nm}$. The slits were set at $10 \mathrm{~nm}$ for excitation and emission. The path length of the sample was $1 \mathrm{~cm}$.

UV Spectra of Cystatin in the Presence of Donepezil. The UV measurement of brain cystatin in the presence and absence of drug was made in the range of $200-300 \mathrm{~nm}$, and the inhibitor (cystatin) concentration was fixed at $1 \mu \mathrm{M}$ while the drug concentration was varied from $0.16 \mu \mathrm{M}-1.6 \mu \mathrm{M}$. Absorption 
spectra were recorded on a double beam Shimadzu UVvis spectrophotometer UV-1700 using a cuvette of $1 \mathrm{~cm}$ path length.

Activity Measurement of Brain Cystatin in the Presence of Donepezil. The inhibitory activity of the purified inhibitor (BC) under native conditions was assessed by its ability to inhibit caseinolytic activity of papain by the method of Kunitz [21]. The inhibitor $(1 \mu \mathrm{M})$ was incubated with increasing concentrations of donepezil at $25^{\circ} \mathrm{C}$ for 30 min before the activity was measured. Activity of untreated BC was taken as $100 \%$.

\section{Results}

3.1. Interaction of Donepezil with Brain Cystatin. Alzheimer disease is a progressive brain disorder that gradually destroys a person's memory and ability to learn, reason, and make judgments. AChE is responsible for degradation of the neurotransmitter acetylcholine ( $\mathrm{ACh})$ in the synaptic cleft of neuromuscular junctions and of neuronal contacts in the central nervous system $[22,23]$. Donepezil belongs to the important class of acetyl cholinesterase inhibitors (AChEIs) [24]. The results of the interaction of donepezil with cystatin are given below.

3.2. Intrinsic Fluorescence Studies of Cystatin in the Presence of Donepezil. Cystatin $(1 \mu \mathrm{M})$ was incubated with various concentrations of donepezil varying from 2 to $10 \mu \mathrm{M}$ for $30 \mathrm{~min}$. The fluorescence was recorded in the wavelength region of $300-400 \mathrm{~nm}$ after exciting the protein solution at $280 \mathrm{~nm}$ for total protein fluorescence. Donepezil caused unfolding of the cystatin as indicated by enhancement in fluorescence intensity accompanied by the red shift of $40 \mathrm{~nm}$ as compared to $\lambda_{\max }$ of native cystatin $(340 \mathrm{~nm})$ while the drug (native) shows $\lambda_{\text {max }}$ at $370 \mathrm{~nm}$. However at $1.6 \mu \mathrm{M}$, when it forms complex with cystatin there was shift in $\lambda_{\max }$ of $10 \mathrm{~nm}$ with significant enhancement in fluorescence intensity (Figure 3).

Cystatin $(1 \mu \mathrm{M})$ was incubated with various concentrations of donepezil varying from $0.16 \mu \mathrm{M}$ to $1.6 \mu \mathrm{M}$ for $30 \mathrm{~min}$. The fluorescence was recorded in the wavelength region 300$400 \mathrm{~nm}$ after exciting the protein solution at $280 \mathrm{~nm}$ for total protein fluorescence. The slits were set at $10 \mathrm{~nm}$ for excitation and emission. The path length of the sample was $1 \mathrm{~cm}$ in the final reaction volume of $1 \mathrm{~mL}$ in $0.05 \mathrm{M}$ sodium phosphate buffer $\mathrm{pH} 7.5$.

3.3. UV-vis Spectra of Cystatin in the Presence and Absence of Donepezil. Cystatin concentrations were fixed at $1 \mu \mathrm{M}$ while the donepezil concentrations varied from $0.16 \mu \mathrm{M}$ to $1.6 \mu \mathrm{M}$. Absorption spectra of native cystatin and in the presence and absence of donepezil were recorded in the range of 200$300 \mathrm{~nm}$. The UV absorption intensity of cystatin increased with increasing concentration of donepezil concentration; however the slight decrease in absorption intensity may be due to disruption or perturbation of absorbing groups (Figure 3).

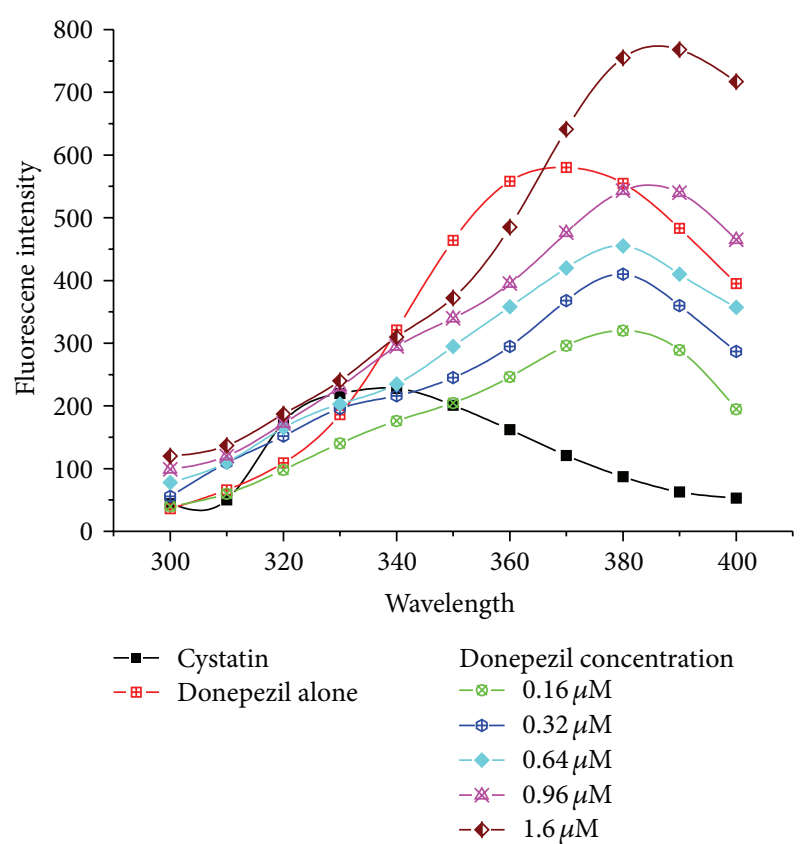

FIGURE 3: Fluorescence spectra of cystatin in the presence and absence of donepezil.

Cystatin concentrations were fixed at $1 \mu \mathrm{M}$ while the donepezil concentration was varied from $0.16 \mu \mathrm{M}$ to $1.6 \mu \mathrm{M}$. Absorption spectra of native cystatin in the presence and absence of donepezil were recorded in the range of 200$300 \mathrm{~nm}$ in a cuvette of $1 \mathrm{~cm}$ path length for $30 \mathrm{~min}$ in the final reaction volume of $1 \mathrm{~mL}$ in $0.05 \mathrm{M}$ sodium phosphate buffer $\mathrm{pH} 7.5$.

3.4. Inhibitory Activity of Cystatin in the Presence of Donepezil. A change in the inhibitory activity of cystatin with increasing concentration of donepezil is shown in (Table 1). Effect of Donepezil on cystatin function was assessed by monitoring its changes in antiproteolytic activity by caseinolytic assay of papain [21]; $1 \mu \mathrm{M}$ of cystatin was incubated with increasing concentration of donepezil $(0.16-1.6 \mu \mathrm{M})$. Exposure of cystatin to increasing concentration of donepezil resulted in rapid decline of antiproteolytic activity; $85 \%$ decline in the activity was seen at $1.6 \mu \mathrm{M}$ of donepezil with more than half of the inactivation of cystatin was taking place at concentration as low as $0.32 \mu \mathrm{M}$.

Table 1 shows changes in the inhibitory activity of brain cystatin after its incubation for its inhibitory activity with increasing concentrations of donepezil. Cystatin $(1 \mu \mathrm{M})$ was treated with varying concentration of donepezil $(0.16 \mu \mathrm{M}-$ $1.6 \mu \mathrm{M}$ ) for $30 \mathrm{~min}$ in the final reaction volume of $1 \mathrm{~mL}$ in $0.05 \mathrm{M}$ sodium phosphate buffer $\mathrm{pH}$ 7.5.

All data are expressed as mean \pm S.E. for three different sets of experiments; statistical significance was conducted employing ONE WAY ANOVA. A probability level of 0.05 was selected showing that results are significant. 
TABLE 1: Inhibitory activity of cystatin in the presence of donepezil.

\begin{tabular}{lcc}
\hline S. no & Drug concentration & \% Remaining inhibitory activity of cystatin \\
\hline 1 & Cystatin alone & 100 \\
2 & Cystatin $+0.16 \mu \mathrm{M}$ donepezil & $57 \pm 0.623$ \\
3 & Cystatin $+0.32 \mu \mathrm{M}$ donepezil & $40 \pm 0.938$ \\
4 & Cystatin $+0.64 \mu \mathrm{M}$ donepezil & $38 \pm 0.772$ \\
5 & Cystatin $+0.96 \mu \mathrm{M}$ donepezil & $24 \pm 0.932$ \\
6 & Cystatin $+1.6 \mu \mathrm{M}$ donepezil & $15 \pm 0.680$ \\
\hline
\end{tabular}

All data are expressed as mean \pm S.E. for three different sets of experiments; statistical significance was conducted employing one way ANOVA. A probability level of 0.05 was selected showing that results are significant.

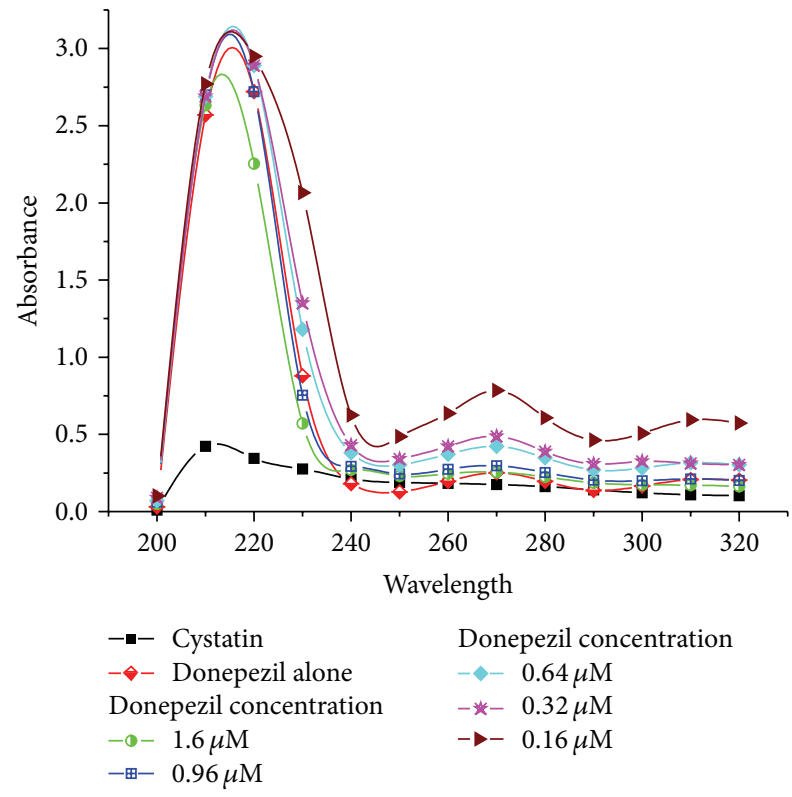

FIGURE 4: UV-vis spectra of cystatin in the presence and absence of donepezil.

\section{Discussion}

Drug inducing changes in protein function leading to adverse side effects is the area of continual scientific investigation [25, 26].

Even small structural differences in protein conformation can lead to drastic changes in functional parameters [26]. Addition of small molecules such as many drugs, particularly those with local anesthetics, tranquillizers, and antidepressants, can bind to the native state and can alter the delicate balance of various interactions in proteins [27-30].

Accumulation of drug molecules at certain sites in the body causes their localized high concentration leading to adverse drug reactions [31] and ligand induced protein structure conformational changes [32]. These are major problems complicating drug medical therapy; therefore investigations which combine the study of the conformational changes in proteins through variations of external parameters between proteins and drugs and the structure of the resulting complexes are of particular interest. These studies enable to elucidate how ligand affinity is regulated and how the protein conformation is altered upon complexation [26] which is of crucial importance in a vast range of important biochemical phenomena.

In the present work, structural and functional analysis of cystatin, a protein ubiquitously present in mammalian cells and tissues, was studied which showed a significant increase in fluorescence intensity due to unfolding of cystatin in the presence of donepezil (Figure 3). Such kind of changes have also been documented earlier, after interaction of ligands (phytohormones, cytokinins, abscisic, and gibberellic acids) with wheat germ agglutinin resulting in $60 \%$ increase in fluorescence intensity of native protein [33].

Donepezil-cystatin complexation showed $40 \mathrm{~nm}$ red shift in $\lambda_{\max }$ indicating exposure of aromatic residues to the solvent caused by conformational changes in the protein $[34,35]$. Absorption spectral measurements of cystatin in the presence of drug showed a peak noticeable at $275 \mathrm{~nm}$ and $210 \mathrm{~nm}$ in spectra obtained at $0.16 \mu \mathrm{M}$ donepezil (Figure 4). suggesting changes mainly due to tryptophan and tyrosine residues [36]. There was a gradual decline in cystatin activity with increasing drug concentration resulting in $62 \%$ loss at $0.64 \mu \mathrm{M}$ donepezil (Table 1). Further magnitude of decline was relatively smaller with increasing drug concentration at $1.6 \mu \mathrm{M}$; cystatin the inhibitor retained only $15 \%$ of its antiproteolytic potential.

Thus, the results indicate that the UV absorption and fluorescence emission changes in donepezil mediated interaction are due to conformational changes in cystatin mainly arising from interaction affecting the chromophoric groups of the protein which produce significant effect on the activity of cystatin. The study shows that in the presence of donepezil, cystatin gets unfolded which is a side effect of donepezil.

The knowledge about the pharmacokinetics and pharmacodynamics of the drug-protein interaction continues to expand. The increased information available to clinicians might help in optimizing the use of these agents in the management of patients with Alzheimer's and other diseases. The clinical utility of measuring these parameters in daily practice awaits further research [37].

\section{Abbreviations}

BC: Brain cystatin

AChE: Acetyl cholinesterase

ACh: Acetylcholine

AD: Alzheimer's disease. 


\section{Acknowledgments}

Facilities provided by Aligarh Muslim University and financial assistance provided by ICMR are gratefully acknowledged.

\section{References}

[1] H. G. Bernstein, H. Kirschke, B. Wiederanders, K. H. Pollak, A. Zipress, and A. Rinne, "The possible place of cathepsins and cystatins in the puzzle of Alzheimer disease," Molecular and Chemical Neuropathology, vol. 27, no. 3, pp. 225-247, 1996.

[2] J. S. Birks, D. Melzer, and H. Beppu, "Donepezil for mild and moderate Alzheimer's disease," Cochrane Database of Systematic Reviews, no. 4, Article ID CD001190, 2000.

[3] H. Sugimoto, H. Ogura, Y. Arai, Y. Iimura, and Y. Yamanishi, "Research and development of donepezil hydrochloride, a new type of acetylcholinesterase inhibitor," Japanese Journal of Pharmacology, vol. 89, no. 1, pp. 7-20, 2002.

[4] D. C. German, U. Yazdani, S. G. Speciale, P. Pasbakhsh, D. Games, and C. L. Liang, "Cholinergic neuropathology in a mouse model of Alzheimer's disease," Journal of Comparative Neurology, vol. 462, no. 4, pp. 371-381, 2003.

[5] Y. Yamanishi, H. Ogura, T. Kosasa, S. Araki, Y. Sawa, and K. Yamatsu, "Inhibitory action of E2020, a novel acetylcholineasterase inhibitor, on cholinesterase: comparison with other inhibitors," in Basic, Clinical, and Therapeutic Aspects of Alzheimer's and Parkinson's Diseases, T. Nagatsu, Ed., vol. 2, pp. 409-413, Plenum Press, New York, NY, USA, 1991.

[6] H. Sugimoto, Y. Iimura, Y. Yamanishi, and K. Yamatsu, "Synthesis and structure-activity relationships of acetylcholinesterase inhibitors: 1-benzyl-4-[(5,6-dimethoxy-1-oxoindan-2yl)methyl]piperidine hydrochloride and related compounds," Journal of Medicinal Chemistry, vol. 38, no. 24, pp. 4821-4829, 1995.

[7] M. Mihara, A. Ohnishi, Y. Tomono et al., "Pharmacokinetics of E2020, a new compound for Alzheimer's disease, in healthy male volunteers," International Journal of Clinical Pharmacology Therapy and Toxicology, vol. 31, no. 5, pp. 223-229, 1993.

[8] S. L. Rogers, M. R. Farlow, R. S. Doody, R. Mohs, L. T. Friedhoff, and The Donepezil Study Group, "A 24-week, doubleblind, placebo-controlled trial of donepezil in patients with Alzheimer's disease," Neurology, vol. 50, no. 1, pp. 136-145, 1998.

[9] S. L. Rogers, R. S. Doody, R. C. Mohs, L. T. Friedhoff, and The Donepezil Study Group, "Donepezil improves cognition and global function in Alzheimer disease: a 15-week, doubleblind, placebo-controlled study," Archives of Internal Medicine, vol. 158, no. 9, pp. 1021-1031, 1998.

[10] J. Birks and R. J. Harvey, "Donepezil for dementia due to Alzheimer's disease," Cochrane Database of Systematic Reviews, no. 1, Article ID CD001190, 2006.

[11] M. W. Jann, K. L. Shirley, and G. W. Small, "Clinical pharmacokinetics and pharmacodynamics of cholinesterase inhibitors," Clinical Pharmacokinetics, vol. 41, no. 10, pp. 719-739, 2002.

[12] H. G. Bernstein and B. Wiederanders, "An immunohistochemical study of cathepsin E in Alzheimer-type dementia brains," Brain Research, vol. 667, no. 2, pp. 287-290, 1994.

[13] I. Ekiel, M. Abrahamson, D. B. Fulton et al., "NMR structural studies of human cystatin C dimers and monomers," Journal of Molecular Biology, vol. 271, no. 2, pp. 266-277, 1997.

[14] J. L. Cox, "Cystatins and cancer," Frontiers in Bioscience, vol. 14, pp. 463-474, 2009.
[15] Z. Grzonka, E. Jankowska, F. Kasprzykowski et al., "Structural studies of cysteine proteases and their inhibitors," Acta Biochimica Polonica, vol. 48, no. 1, pp. 1-20, 2001.

[16] E. Levy and C. Cystatin, "A potential target for Alzheimer's treatment," Expert Review of Neurotherapeutics, vol. 8, no. 5, pp. 687-689, 2008.

[17] R. Gotti, C. Bertucci, V. Andrisano, R. Pomponio, and V. Cavrini, "Study of donepezil binding to serum albumin by capillary electrophoresis and circular dichroism," Analytical and Bioanalytical Chemistry, vol. 377, no. 5, pp. 875-879, 2003.

[18] V. Turk and B. Turk, "Lysosomal cysteine proteases and their protein inhibitors: recent developments," Acta Chimica Slovenica, vol. 55, no. 4, pp. 727-738, 2008.

[19] A. Shah and B. Bano, "Cystatins in health and diseases," International Journal of Peptide Research and Therapeutics, vol. 15, no. 1, pp. 43-48, 2009.

[20] F. Amin, A. A. Khan, S. J. Rizvi, and B. Bano, "Purification and characterization of buffalo brain cystatin," Protein and Peptide Letters, vol. 18, no. 2, pp. 210-218, 2011.

[21] M. Kunitz, "Crystalline soybean trypsin inhibitor II. General properties," Journal of General Physiology, vol. 30, no. 4, pp. 291310, 1947.

[22] P. Kasa, H. Papp, P. Kasa Jr., and I. Torok, "Donepezil dosedependently inhibits acetylcholinesterase activity in various areas and in the presynaptic cholinergic and the postsynaptic cholinoceptive enzyme-positive structures in the human and rat brain," Neuroscience, vol. 101, no. 1, pp. 89-100, 2000.

[23] N. Tabet, "Acetylcholinesterase inhibitors for Alzheimer's disease: anti-inflammatories in acetylcholine clothing!" Age and Ageing, vol. 35, no. 4, pp. 336-338, 2006.

[24] J. Kaur and M. Q. Zhang, "Molecular modelling and QSAR of reversible acetylcholines-terase inhibitors," Current Medicinal Chemistry, vol. 7, no. 3, pp. 273-294, 2000.

[25] S. Priyamvada, M. Priyadarshini, N. A. Arivarasu et al., "Studies on the protective effect of dietary fish oil on gentamicininduced nephrotoxicity and oxidative damage in rat kidney," Prostaglandins Leukotrienes and Essential Fatty Acids, vol. 78, no. 6, pp. 369-381, 2008.

[26] K. Sneppen and G. Zocchi, Physics in Molecular Biology, Cambridge University Press, New York, NY, USA, 1st edition, 2005.

[27] A. Salvi, P. Carrupt, J. Tillement, and B. Testa, "Structural damage to proteins caused by free radicals: asessment, protection by antioxidants, and influence of protein binding," Biochemical Pharmacology, vol. 61, no. 10, pp. 1237-1242, 2001.

[28] M. Guo, J. W. Zou, P. G. Yi, Z. C. Shang, G. X. Hu, and Q. $\mathrm{S}$. Yu, "Binding interaction of gatifloxacin with bovine serum albumin," Analytical Sciences, vol. 20, no. 3, pp. 465-470, 2004.

[29] M. A. Cheema, P. Taboada, S. Barbosa et al., "Energetics of binding and protein unfolding upon amphiphilic drug complexation with a globular protein in different aqueous media," Colloids and Surfaces B, vol. 63, no. 2, pp. 217-228, 2008.

[30] A. Ahmed-Ouameur, S. Diamantoglou, M. R. Sedaghat-Herati, S. Nafisi, R. Carpentier, and H. A. Tajmir-Riahi, "The effects of drug complexation on the stability and conformation of human serum albumin: protein unfolding," Cell Biochemistry and Biophysics, vol. 45, no. 2, pp. 203-213, 2006.

[31] Z. M. Wen and S. T. Ye, "Skin testing in patients with high risk of anaphylactic reactions to penicillin," Asian Pacific Journal of Allergy and Immunology, vol. 11, no. 1, pp. 13-18, 1993. 
[32] K. Takeda, A. Wada, K. Yamamoto, K. Hachiya, and P. P. Batra, "Secondary structure change of myoglobin induced by sodium dodecyl sulfate and its kinetic aspects," Journal of Colloid And Interface Science, vol. 125, no. 1, pp. 307-313, 1988.

[33] V. P. Bogoeva, M. A. Radeva, L. Y. Atanasova, S. R. Stoitsova, and R. N. Boteva, "Fluorescence analysis of hormone binding activities of wheat germ agglutinin," Biochimica et Biophysica Acta, vol. 1698, no. 2, pp. 213-218, 2004.

[34] E. Monsellier and H. Bedouelle, "Quantitative measurement of protein stability from unfolding equilibria monitored with the fluorescence maximum wavelength," Protein Engineering, Design and Selection, vol. 18, no. 9, pp. 445-456, 2005.

[35] J. T. Vivian and P. R. Callis, "Mechanisms of tryptophan fluorescence shifts in proteins," Biophysical Journal, vol. 80, no. 5, pp. 2093-2109, 2001.

[36] J. W. Donovan, "Ultraviolet difference spectroscopy-new techniques and applications," Methods in Enzymology, vol. 27, pp. 497-525, 1973.

[37] M. L. Crismon, "Pharmacokinetics and drug interactions of cholinesterase inhibitors administered in Alzheimer's disease," Pharmacotherapy, vol. 18, no. 2, pp. 47-54, 79-82, 1998. 


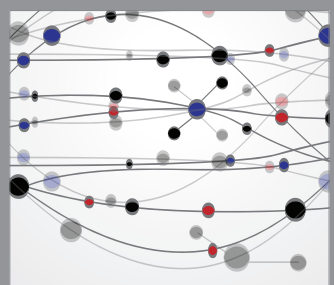

The Scientific World Journal
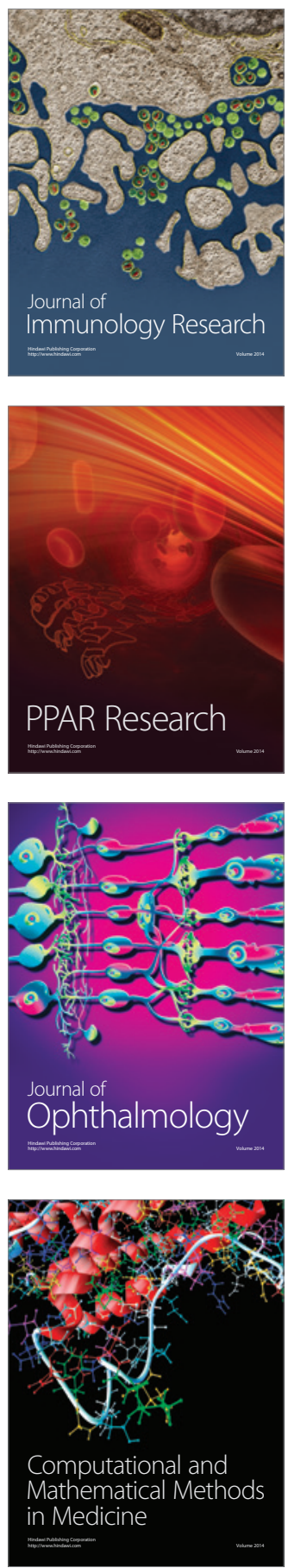

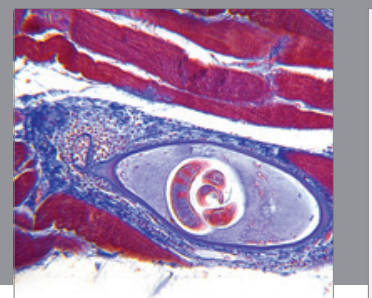

Gastroenterology

Research and Practice
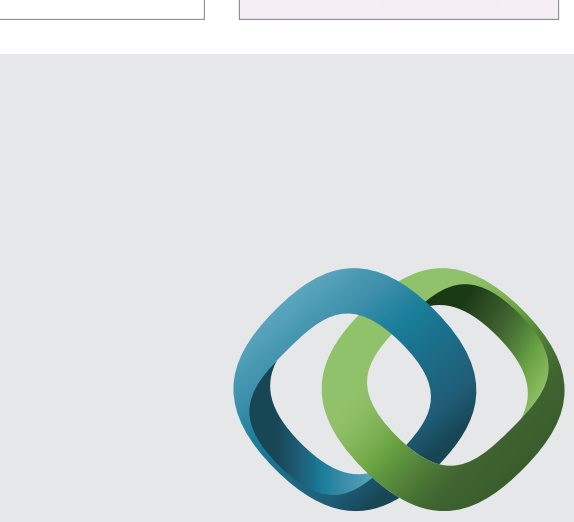

\section{Hindawi}

Submit your manuscripts at

http://www.hindawi.com
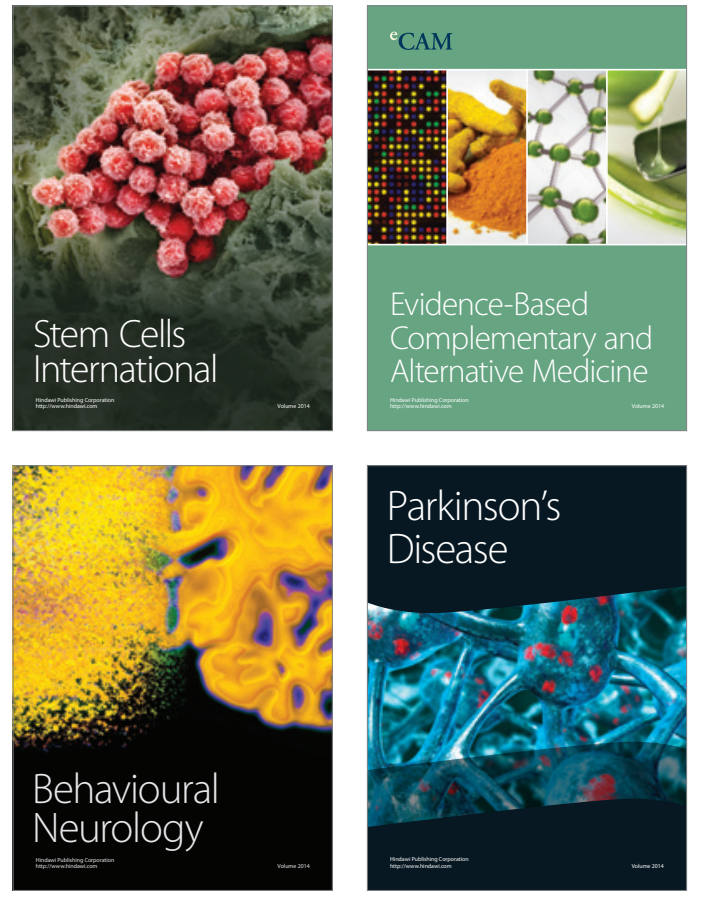
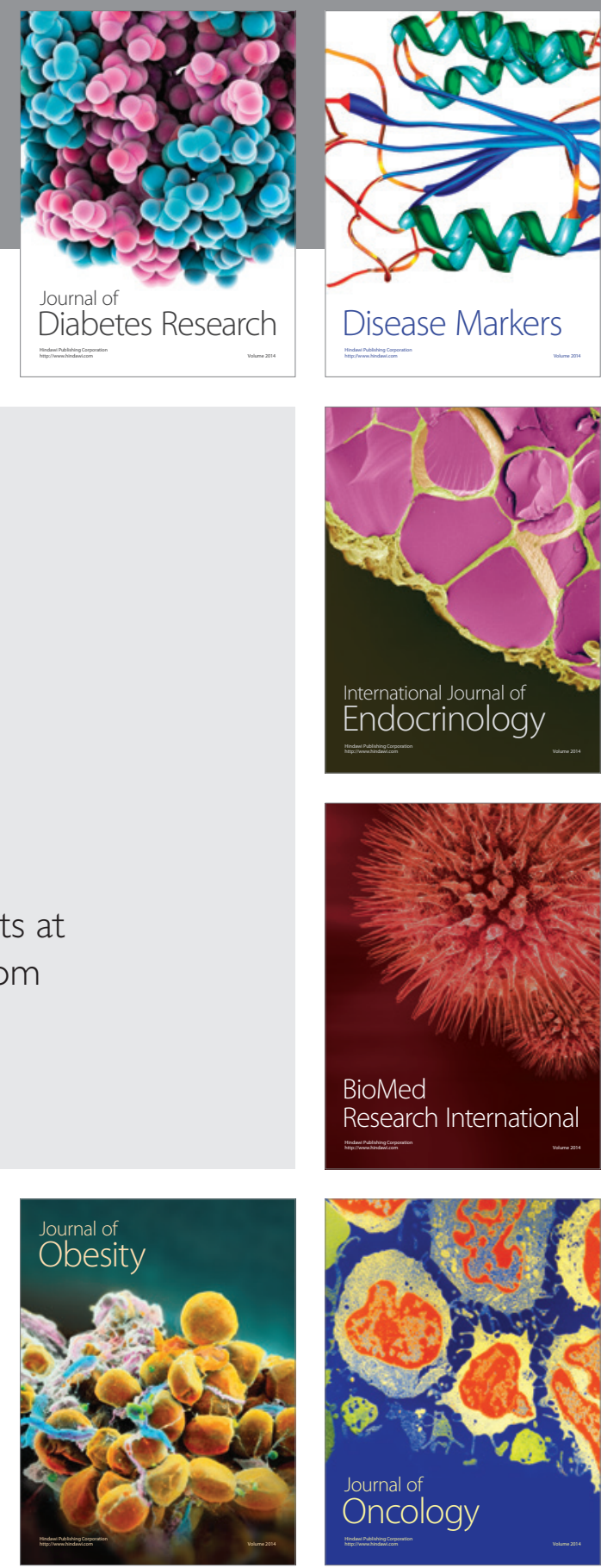

Disease Markers
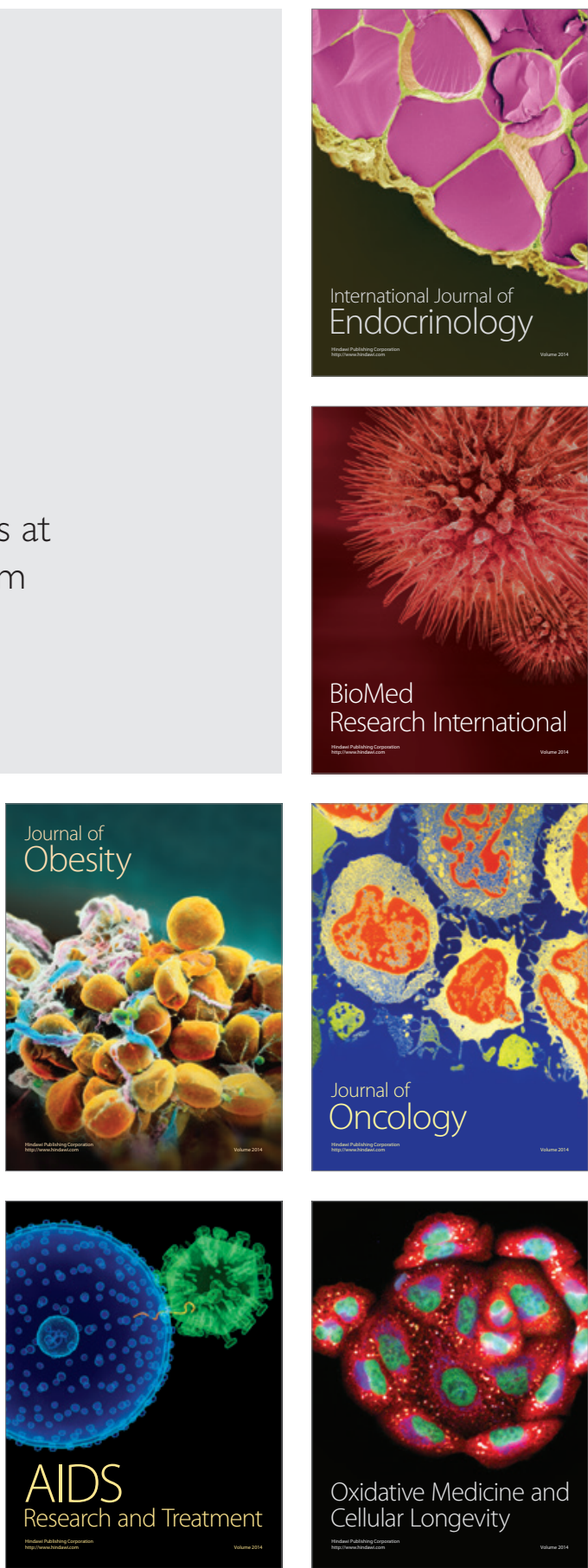